\title{
Bilgisayar destekli heksapodal eksternal fiksatörlerle deformite düzeltme
}

\section{Deformity correction with computer assisted hexapodal external fixators}

\author{
Salih Marangoz \\ Acıbadem Mehmet Ali Aydınlar Üniversitesi Tıp Fakültesi, Ortopedi ve Travmatoloji Anabilim Dalı, İstanbul
}

\begin{abstract}
Bilgisayar destekli sirküler eksternal fiksatörler temel ilizarov prensipleri doğrultusunda deformitenin üç planda ve altı eksen etrafında çerçevede değişikliğe gitmeye gerek kalmaksızın aynı anda uzaysal olarak düzeltilmesine olanak sağlamaktadırlar. Heksapodal eksternal fiksatörler altı serbestlik derecesi (df) örneği olan Stewart-Gough platformu üzerine geliştirilmiştir. Bunun matematiksel alt yapısı ise Chasles teoremine dayanmaktadır. Günümüzde ekstremite rekonstrüksiyon cerrahisinin en önemli hedefi öngörülebilir komplikasyonları en aza indirmek, tedavi süresini azaltmak ve hastayı bir an önce normal fonksiyonel aktivite düzeyine döndürmektir. Heksapodların en büyük avantajı ise kompleks deformiteleri düzeltirken klasik İlizarov çerçevelerinden farklı olarak sanal menteşe etrafında uzaysal olarak yer değiştirmeye olanak sağlamaları ve bu sayede metal aksamın değiştirilmesine gerek kalmaksızın istenilen düzeltmelerin daha kısa süre zarfında yapılabilmesine olanak sağlamalarıdır. Heksapodların ortak özelliği donanımsal olarak aralarında altı çubuk (strut) ile birbirine bağlanan iki tane halkadan oluşmalarıdır. Yazılımsal olarak deformite doğru bir şekilde tanımlanmalı ve halkaların ekstremiteye monte edilmesi sonrasında uzaysal olarak konumunu belirleyen montaj parametrelerinin titiz bir şekilde belirlenmesi gereklidir.
\end{abstract}

Anahtar sözcülkler: bilgisayar destekli eksternal fiksatör; heksapod; Taylor uzaysal çerçevesi (Taylor Spatial Frame (TSF)); Smart Correction; Spider Frame
Computer assisted circular external fixators offer spatial deformity correction following Ilizarov principles in 3 planes around 6 axes without the need to revise major external fixator frame parts. Hexapodal external fixators were developed according to Stewart-Gough platform which is an example of 6 degrees of freedom ( $d f$ ). Mathematical background is based on Chasles theorem. Today, the goal of the limb reconstruction surgeon is to minimize the preventable complications, decrease the treatment time and return the patient to normal functional activity level as soon as possible. The major advantage of hexapods is the fact that they allow spatial corrections of the complex deformity around a virtual hinge in the minimum time possible. They also offer this to be performed in a shortened duration compared to classical Ilizarov frames in which the frames have to be revised many times during the course of correction. Common characteristics of hexapods are the two rings construct that are attached together with 6 struts that have universal joints. Deformity should be defined accurately in the software, along with the mounting parameters, which determine the spatial location of the frame with reference to bone. The more precise it is done, the better the accuracy of the correction is, and likewise, the less the need of the residual correction is.

Key words: computer assisted external fixator; hexapod; Taylor Spatial Frame (TSF); Smart Correction; Spider Frame

\section{TARIHSEL GELIŞiM VE GÜNCEL DURUM}

ilizarov ile farklı düzlemlerde deformite düzeltmesi yapılırken angulasyon, rotasyon ve translasyon için ayrı ayrı ilizarov parçaları ile sistem kurgulanmalı ve her bir deformite teker teker düzeltilmelidir. Bu da hasta ve cerrah açısından bazı zorluklar getirmekte idi. Çoğu zaman bu rotasyon ve translasyon mekanizmalarının kurulma aşaması için hastanın yeniden anestezi alması gerekmekte idi..1,2] Bilgisayar destekli fiksatörler sanal bir nokta etrafında üç boyutlu olarak gereken tüm düzeltmeyi vektörel bir şekilde tek seferde yapabilmektedirler. Bu da onların özellikle birden fazla komponenti olan deformitelerde tercih edilmesinde en önemli neden olmuştur. ${ }^{[3,4]}$ Bilgisayar destekli fiksatörler günümüzde sıklıkla kullanılır hale gelmiş, deformite düzeltme cerrahisinin en önemli ve en

- İletişim adresi: Prof. Dr. Salih Marangoz, Acıbadem Mehmet Ali Aydınlar Üniversitesi, Tıp Fakültesi, Ortopedi ve Travmatoloji Anabilim Dalı, İstanbul Tel: 0212 - 4044040 e-posta: drsalihmarangoz@gmail.com

- Geliș tarihi: 6 Aralık 2019 Kabul tarihi: 4 Șubat 2020 


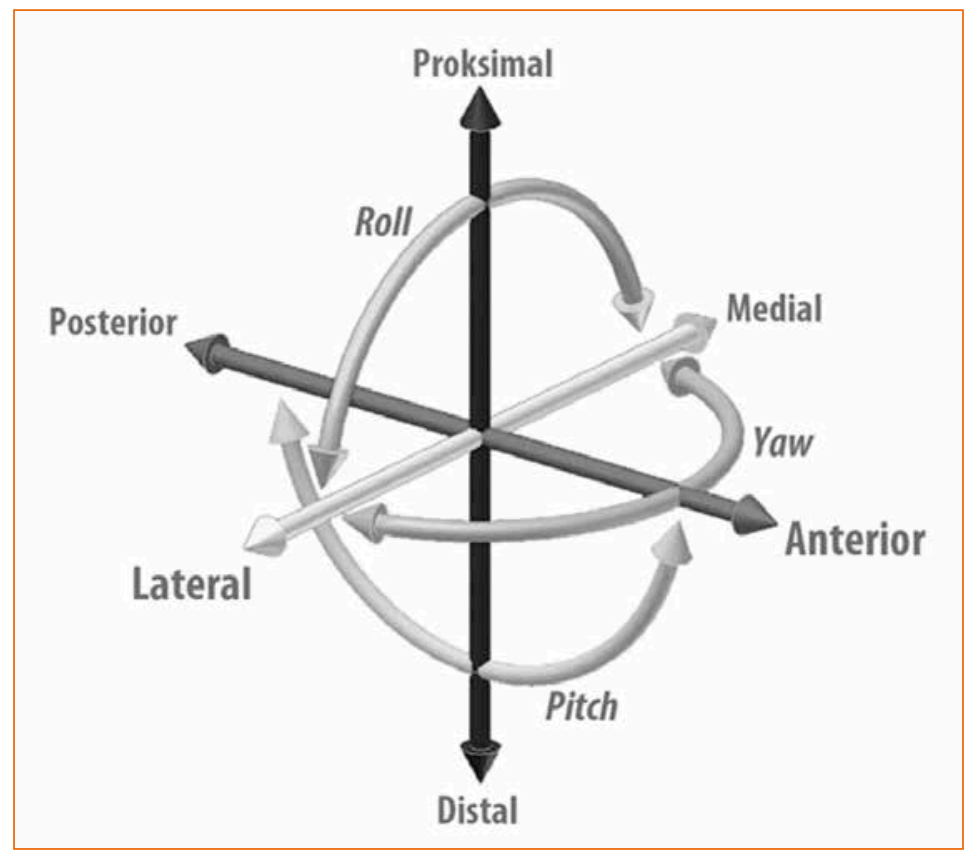

Şekil 1. Üç translasyon ve üç rotasyon ekseninin grafik olarak gösterimi: $x, y$ ve $z$ eksenlerinde $(+)$ ve (-) yönlerde hareket translasyonu göstermektedir. "Roll” aksiyel dönmeyi yani varus-valgusu, "yaw" horizontal dönmeyi yani internal-eksternal rotasyonu, "pitch" ise vertikal dönmeyi yani prokurvatum-rekurvatumu tarif eder. (http://en.wikipedia. org/wiki/Six_degrees_of_freedom)

güçlü araçlarından birisi olmuştur. ${ }^{[5]}$ Bilgisayar destekli fiksatörler denilince akla ilizarov sirküler eksternal fiksatörlerinin modern versiyonu olan heksapodlar gelmektedir. Heksapodlar iki adet halka ve bunları birbirine bağlayan hareketli bağlantı noktalarına sahip altı ayaktan oluşmaktadır. Her bir çubuğun (strut) boyu değişebilir özellikte olup, halkaya bağlandığı yerdeki eklemlerinin hareketli olması sayesinde de iki halkanın birbirine göre üç planda (koronal, sagittal ve transvers) hareket etmesine olanak sağlar. Günlük hayatımızda aslında heksapodal sistemlerin farklı örneklerini görmek için etrafımıza bakmamız yeterlidir. Lunaparklardaki bazı eğlence araçları, üç boyutlu harekete izin veren oyun konsolları, endüstrideki robotik kollar ve uçuş simülatörleri aynı prensiplere dayalı çalışmaktadırlar. Temel olarak Stewart'ın 1965 yılında, Gough ve Whitehall'ın da yine 1960'lı yıllarda öne sürdükleri ve geliştirdikleri tasarımlarla bugün Stewart-Gough platformu olarak bilinen bu yapı, taban ve platform olarak bilinen iki temel ve arasında uzanan, boyu değişebilen altı bacaktan oluşmakta ve bu sayede tıbbi ve tıp dışı heksapodların tümüne esas oluşturmaktadır. Altında ciddi bir matematik olan bu cihazların tarihçesi 17. yüzyıla kadar uzanmaktadır.
Desargues ve Pascal bu konuda ilk yayınlayanlar olmakla birlikte Chasles ve Poinsot, bu bilgileri gün ışığına çıkararak yaygınlaştırmışlar, teoremleri ışı̆̆ında uzaysal olarak herhangi bir nesnenin altı eksen etrafında (üç translasyon ve üç rotasyon ekseni) (Şekil 1) yer değiştirmesini açıklayan projektif geometriyi geliştirmişlerdir. ${ }^{[6,7]}$

Altı serbestlik derecesine (six degrees of freedom) sahip olan bu cihazların Ortopedi ve Travmatoloji alanında kullanılması 1980'li yılları bulur. Illk olarak Sovyetler Birliği'nden (Moldova) Pyslar-SmatatinRaku-Vlas-Tomilin 1984 yılında $^{[8]}$, hemen ertesi yıl ise Fransa'dan Havacılık ve Uzay Mühendisi olan Phillippe Moniot, ilizarov cihazına monte edilebilen cihazı için 1985 'te patent almıştır. ${ }^{[7]} \mathrm{Bu}$ cihazlar matematiksel yazılıma ihtiyaç duymaksızın altı çubuk üzerinden altı eksende düzeltme yapmaları açısından önemlidir. ABD, Memphis, Tennessee'den Taylor kardeşlerin 1994 yılında geliştirdiği Taylor Uzaysal Çerçevesi (Taylor Spatial Frame - TSF, Smith and Nephew Orthopaedics, Memphis, TN) (Şekil 2), uzaysal düzeltmeyi, geliştirilen yazılım ile yapması sebebiyle bilgisayar destekli eksternal fiksatörlerle ilgili yeni bir çağın başlamasını sağlamıştır. ${ }^{[9]}$ 


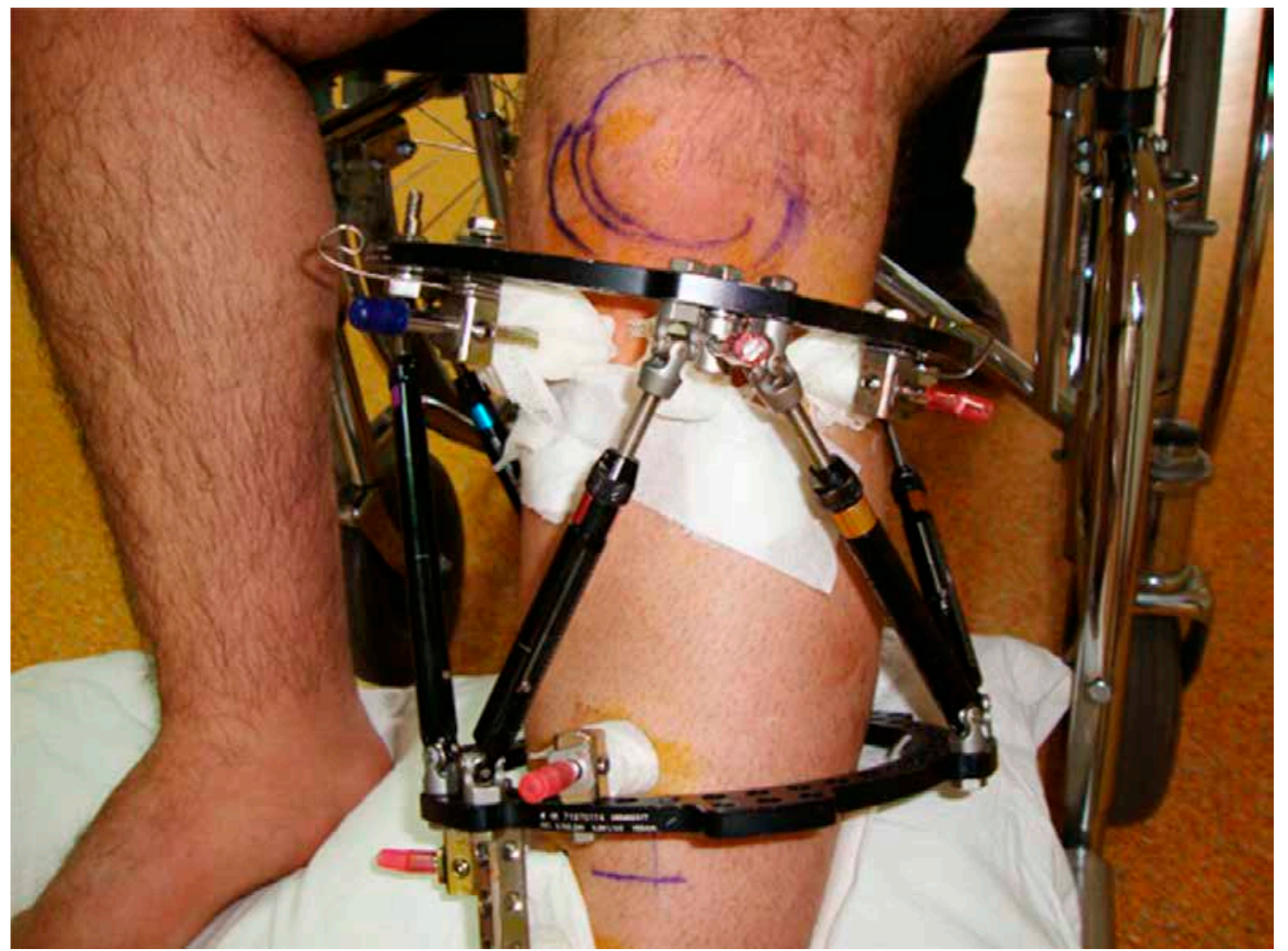

Şekil 2. Taylor Uzaysal Çerçevesi (Taylor Spatial Frame) - 21 yaşında bir erkek hastanın sol tibiasına yerleştirilmiş.

Önceleri bilgisayar tabanlı yapılan yazılımlarını ilk olarak 2002'de internet tabanlı yazılıma geçirmişlerdir. Bu gelişmelerden bağımsız olarak 1996 yılında Almanya'dan Seide ve Wolter ${ }^{[10]}$ klasik ilizarov çerçevesine monte edilebilecek dışarıdan bağlantı aparatları ile altı eksen düzeltmesi yapabilecek kendi cihazlarını geliştirmişlerdir. Hexapod (Lithos, Hamburg, Almanya) ismi verilen bu cihazın TSF'ye göre avantajı klasik ilizarov halkalarına uygulanabilmesi ve 0,1 $\mathrm{mm}$ kadar hassas ayar yapılabilmesidir. Almanya'dan 1998 yılında geliştirilen bir diğer heksapodal fiksatör Eisenberg fiksatörü olarak bilinen cihazdır. Aşağı yukarı 15 yıl boyunca neredeyse tek başına hüküm süren TSF, gelmiş geçmiş en fazla vaka ve yayın sayısına sahip heksapodal fiksatördür. 2009 yılında Türkiye'den donanımı ve yazııımı ile öne çıkan iki fiksatör geliştirilmiştir. Birisi Smart Correction (ilerimed, Response Ortho - A Wishbone Medical Company) olarak bilinen TSF'ye benzeyen bir fiksatördür. Yine iki halka ve bunları birbirine bağlayan universal eklemli altı çubuktan oluşur (Şekil 3). Ancak en büyük avantajı TSF'de mevcut olan bazı kısıtlılıkları aşabilmiş olmasıdır. O da halkanın referans alınan segmente ortogonal (dik) olarak fiksasyon yapılma zorunluluğunu ortadan kaldırmış olması ve montaj parametresi hesaplanmasına gerek kalmaksızın bunu halkaların ve çubukların uzaysal konumuna göre otomatik olarak hesaplayan bir yazılım geliştirmiş olmasıdır. ${ }^{[11-13]}$ 2009 yılında piyasaya sürülen Türkiye menşeli diğer fiksatör ise Adam Frame (Imed Surgical) ismindeki oktopodal bir fiksatördür. Gelmiş geçmiş tek oktopodal fiksatör olması önemli bir özelliğidir (Şekil 4).

Stewart-Gough platformunu esas almasına karşın klasik ilizarov çerçevesi gibi iki halkayı birbirine bağlayan ancak hareketli eklemi olan dört tane vertikal kolu ve bu vertikal kollara bağı olan daha kısa dört tane diagonal (oblik açılı) kollardan oluşması oktopodal dizayn olarak avantajını oluşturmaktadır. Yazılımsal olarak işaret edip klikleme şeklinde röntgen üzerinden bütün hesaplamaları ilave montaj parametresi girilmesine gerek kalmaksızın hesaplayabilmiş olması da yine mevcut sistemler içerisinde öne çıkmasını sağlamıştır. Adam Frame piyasada devamlılığı sağlayamamış ve şu anda üretimi durmuştur. 2010 yılında Rusya'dan patent alan bir diğer ürün ise OrthoSUV (Ortho-SUV Ltd, St. Petersburg, Rusya) olarak bilinen cihazdır. ${ }^{[14-16]}$ Klasik İlizarov veya monolateral eksternal fiksatörlere dahi bağlanabilen, yazılımı için internet gereksinimi 

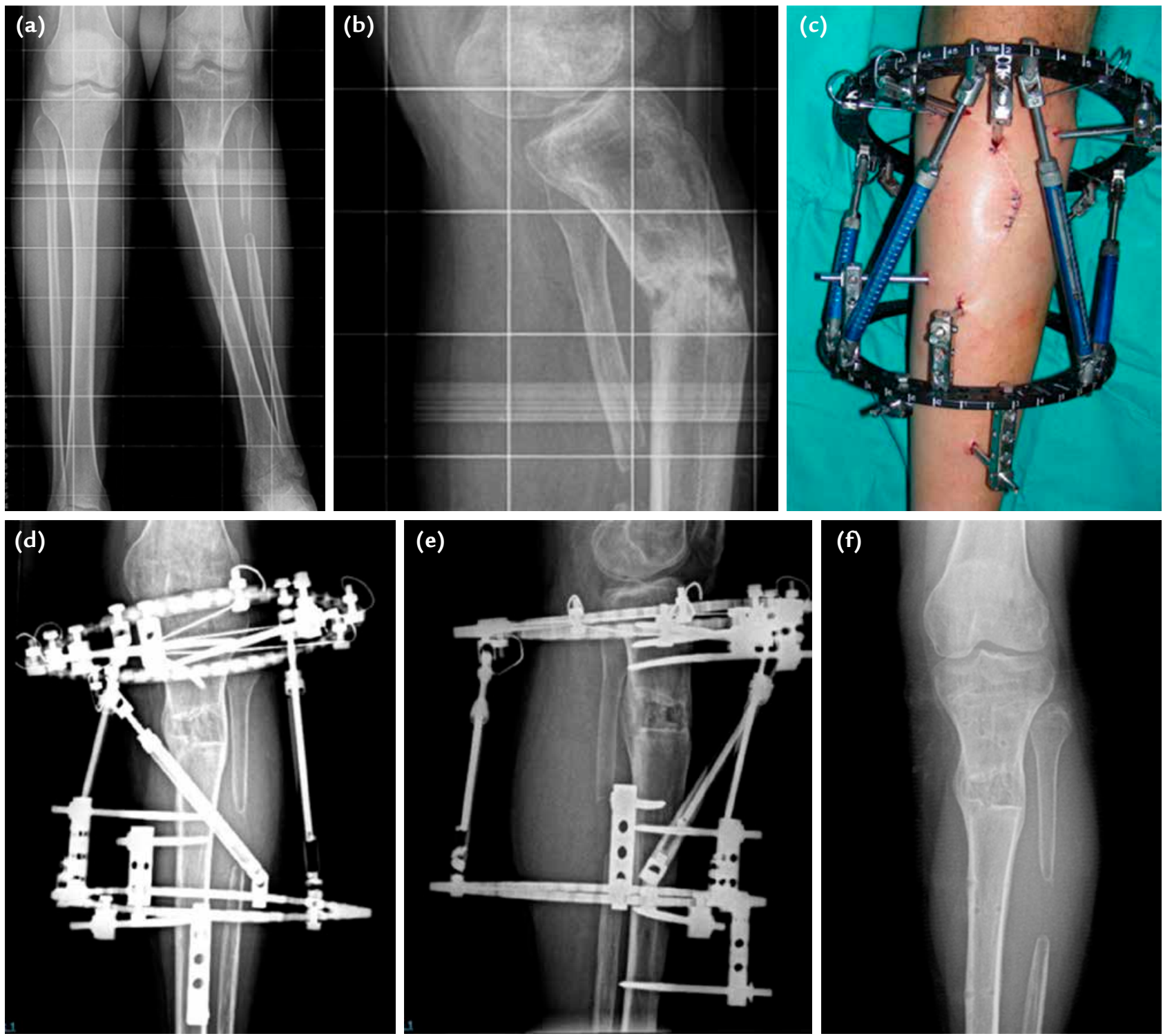

(g)

Şekil 3. a-g. Smart Correction - daha önce monolateral eksternal fiksatörle uzatma girişimi yapılan 18 yaşında bir erkek hastada uygulanması. Apeks anterolateral deformitenin ve kısalığın düzeltilmesi görülüyor. Röntgen çekilirken halkaya dik çekme zorunluluğu yoktur.

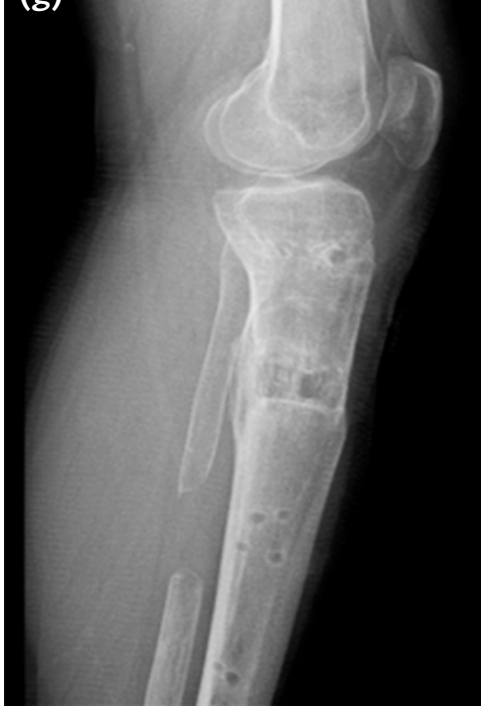

duyulmayan bir fiksatördür. Her bir halkaya sadece üç çubuk bağlanmaktadır. Geriye kalan üç çubuk halkaya bağlanan çubuklara yandan bağlanmaktadır. Bu sayede farklı bir matematiksel yazılım geliştiren bu ürün, oluşan üçgenler üzerinden bir hesaplama yapar, halkaların çapından ve şeklinden bağımsız çalışması da onu en fazla modüler sistem haline getirmektedir. 2011 yılında Türkiye'de geliştirilen üçüncü fiksatör ise Spider Frame'dir (Tasarımmed, İstanbul). TSF gibi benzer özelliklere sahip olmasının yanı sıra çubukların yazılımsal yerleşimi farklıdır (Şekil 5). 


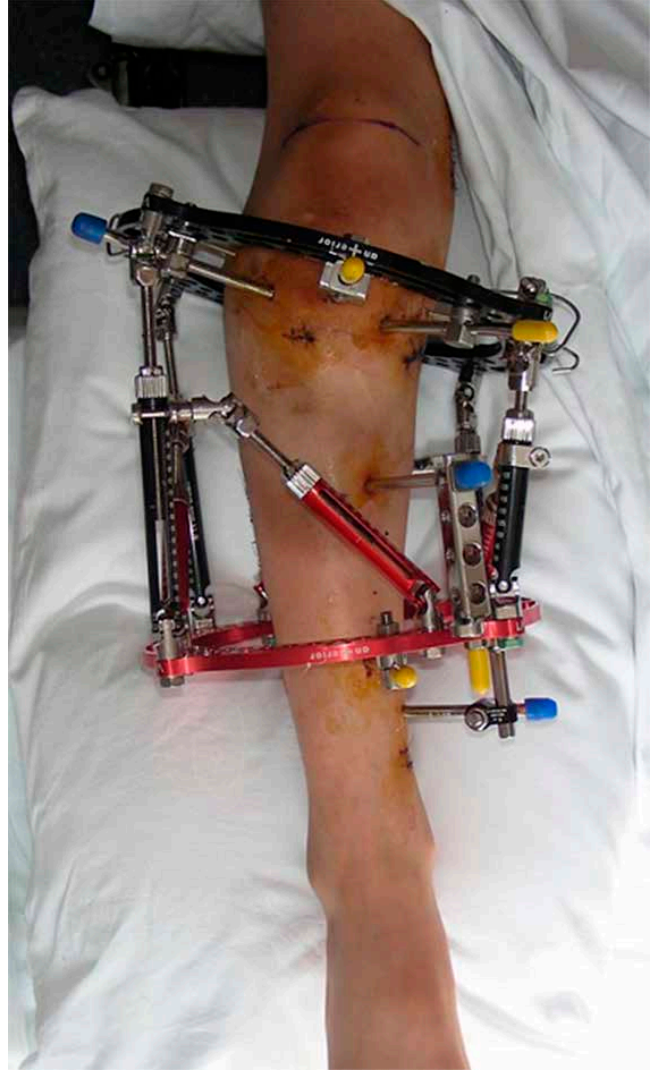

Şekil 4. Adam Frame - oktopodal eksternal fiksatör uygulamasına bir örnek.
2012 yılında geliştirilen bir başka heksapod TL-Hex (Truelok Hexapod, Orthofix S. R. L., Bussolengo, Verona, İtalya) ${ }^{[17-19]}$ TSF yazılımında o zamana kadar yer almayan bir özelliği avantaj olarak kullanıcılarına sunmuştur. O da referans halkası olarak belirlenen halka eğer kemiğe ortogonal olarak monte edilmediyse koronal ya da sagittal planda kaç derece açıda olduğunun hesaplanıp sisteme girilmesine izin vermesi idi. ${ }^{[20]}$ TL-Hex'in donanımsal olarak bir diğer farklılığı ise çubukların halkaların deliklerine değil halkalara yandan bağlanması idi. Bu sayede halkalar arası mesafenin çok daha kısa tutulmasını mümkün hale getirmiştir. [21] 2015 yılından sonra ABD'de hemen her büyük firmanın bir heksapodal fiksatörü piyasaya çıkmaya başlamıştır: Hoffman LRF Hexapod (Stryker), Maxframe (Depuy Synthes), Orthex (Vilex - An OrthoPediatrics Company). Her bir fiksatörün donanımsal ve yazılımsal olarak kendine has özellikleri vardır. Ancak ortak özellikleri donanımsal olarak iki halka ve altı çubuktan oluşması, yazılımsal olarak ise deformitenin altı eksen etrafında manuel olarak düzeltilmesine olanak sağlamasıdır. Yakın gelecekte bu fiksatörlerin üzerlerindeki çubukların otomatik olarak kumanda ile kontrol edilebilmesi mümkün gözükmektedir. Buna yönelik geliştirilen Orthospin (İsrail) ismindeki ürün gelecek vadetmektedir.
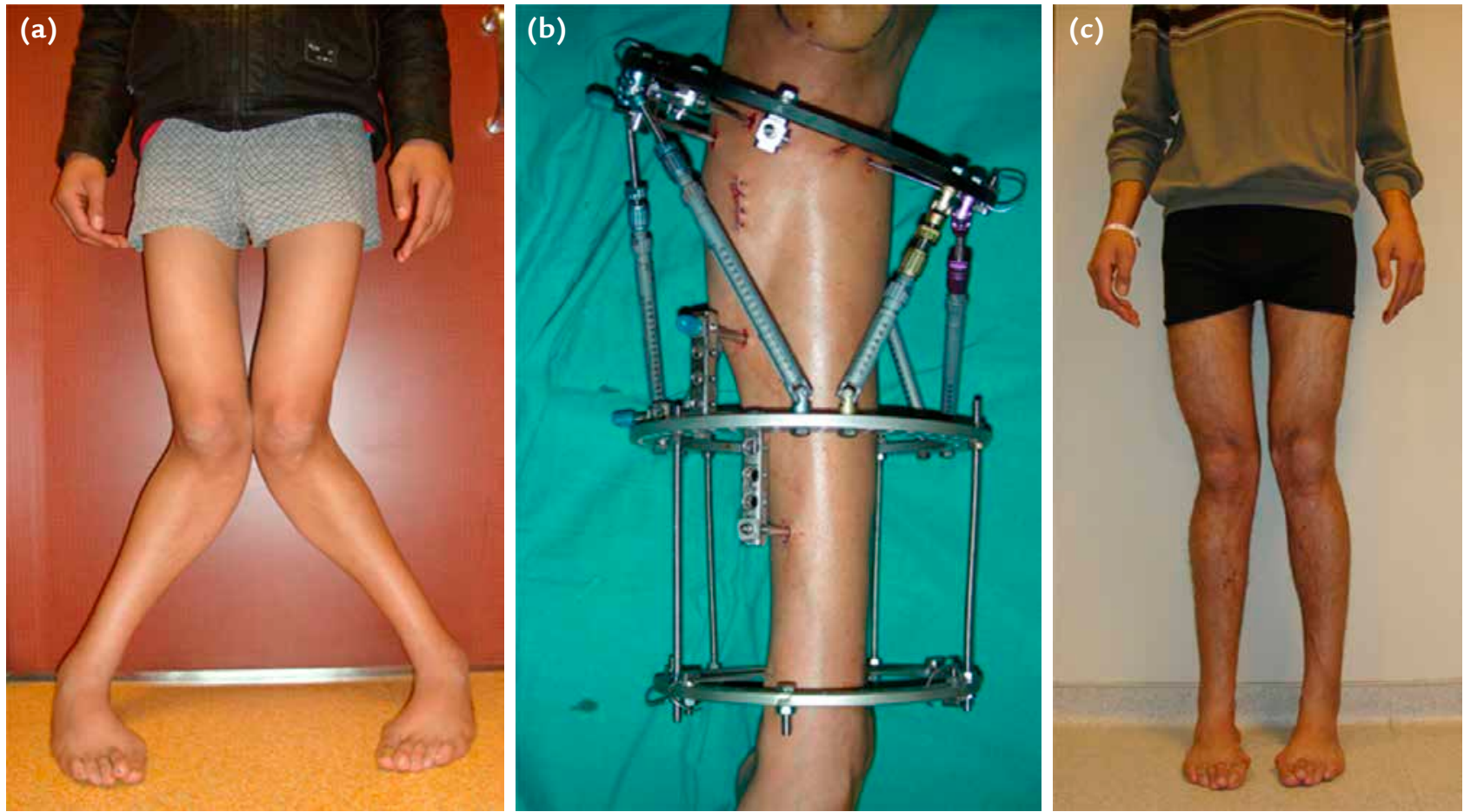

Şekil 5. a-c. Spider Frame - Pyle hastalığı olan 15 yaşında bir erkek hastada peroneal dekompresyon sonrası fiksatörün uygulanması ve düzeltme sonundaki durumu. Metafizyel displazisi olan bu hastada fiksatörün distalinden kırık oluşma riskini azaltmak için çerçeve standart ilizarov parçalarıyla distale uzatılmış. 


\section{HEKSAPODAL FIKSATÖRÜN UYGULANMASI}

Bilgisayar destekli heksapodal fiksatör uygulanacak hastanın analizi klinik değerlendirme ile başlar. ilizarov uygulaması için gerekli psikososyal şartlar ve gereksinimler bilgisayar destekli fiksatörler için de geçerlidir. Hastanın klinik ve radyolojik incelemelerinin yapılması ile deformite tüm komponentleri ile ortaya konur. Ameliyat öncesi deformiteye göre çerçeve kurulumu yapılabileceği gibi ameliyat sırasında da bu kurulum yapılabilmektedir. Yazarın tercihi ameliyatta adım adım bu çerçevenin kurulmasıdır (rings first method). ${ }^{[22]}$ Röntgenlerin preoperatif olarak incelemesi sırasında klasik röntgenlerin çıktıları üzerinden şablon çıkartarak planlama yapılabileceği gibi günümüz dijital çağında röntgenlerin resim işleme programları ve çevrimiçi (online) yazılımlarla da incelenmesi ve planlama yapılması mümkündür. Bu açıdan mevcut olan seçenekler arasında standart bir PACS (Picture Archiving and Communication Systems - Görüntü Saklama ve Illetişim Sistemleri) uygulamasının yanı sıra Bone Ninja (iPad uygulaması), Click2Correct (ücretsiz online yazılım, www.click2correct.com), TraumaCad (Lisanslı yazılım, Brainlab), HexRay (Orthofix) vb. sayılabilir. Önceden yapılan preoperatif deformite analizi ve planlama neticesinde cerrahi uygulanır. ${ }^{[6,23]}$ Bilgisayar destekli heksapodal fiksatörlerde temel olarak altı çubuğu birbirine bağlayan iki tane halka vardır. Bu halkaların yazılım öyle gerektirse de gerektirmese de ilgili anatomik segmentlere ortogonal olarak koyulmaya çalışılması genellikle tavsiye edilir. Bu, düzeltme sırasında hasta konforunu artırır ve düzeltme sonrasında da daha estetik görünümlü çerçeveler elde edilmesine olanak sağlar. Yazılımı referans halka kavramına dayalı olan fiksatörlerde referans halkasını ilgili segmente tam dik olarak (ortogonal) yerleştirmek zaruridir. Aksi takdirde ortaya çıkacak rezidüel deformiteler de ayrıca düzeltilmek zorunda kalınabilir. Tibia için örnek verilirse tavsiye edilen yöntem; öncelikle ekleme paralel veya medialde $3^{\circ}$ daha proksimalde olacak şekilde bir adet $1,8 \mathrm{~mm}$ tel yerleştirilmesi, ardından bacak çapına uygun olacak şekilde bir halkanın bu tel üzerinden tespit edilmesidir. $\mathrm{Bu}$ tespitin ardından delta konfigürasyonuna uygun olacak şekilde öncelikle bir adet Schanz vidası halkanın tam ortasından kemiğe dik bir biçimde çift korteks tutulacak şekilde konulmalıdır. Bir tel ve bir Schanz ile hem koronal hem de sagittal planda tespitin yapılmasının ardından, distal segmentin halkaya fiksasyonuna geçilebilir. Distal segmentteki halkanın bacağı tam ortalayacak şekilde yerleştirilmesinin ardından bu iki halka, arasındaki çubuklarla birbirine bağlanır. Bu sayede daha fazla fiksasyon yapılırken çubukların geçeceği trasenin yanlışıkla engellenmesi önlenmiş olur. Çubukların bağlanmasının ardından kalan boşluklardan delta konfigürasyonuna uygun olacak şekilde hem proksimalde hem de distalde fiksasyon tamamlanır. Çoklu drilleme ile osteotomi yapılacaksa bu aşamada çubuklar çıkarılır. Yapılacak insizyonu takiben çoklu drill osteotomisi tamamlanır. Eğer Gigli osteotomisi ile osteotomi planlanmış ise ameliyatın en başında veya en geç proksimaldeki fiksasyonun yapılmasının ardından osteotomi hattından Gigli teli geçirilerek ameliyat sonunda kullanmak üzere hazır edilir. Yapılacak düzeltme ve gereklilik durumuna göre fibula osteotomisi öncesinde yapılmalı, proksimal ve distal tibiofibular geçici fiksasyon planlanmalıdır. Bilgisayar destekli fiksatörlerde kullanılacak markanın yazılımına göre değişmekle birlikte montaj parametresi hesaplanması gereken durumlarda bunu referans halkaya göre ameliyat sırasında floroskopi ile de yapmak mümkündür. Bunun için referans halkasının ve deformitenin apeksinin aynı anda görülebileceği bir kesitin, büyüklüğü bilinen bir cisim X-ışınına göre kemikle aynı mesafede tutulurken, alınması önerilir. Röntgen çekimi sırasında da yine kullanılacak ürüne göre değişmekle birlikte referans halkasına ortogonal olarak röntgen çekilmesi gerekli durumlarda referans halkasının düz bir çizgi gibi görünecek şekilde ayarlama yapılarak röntgen çekilmesi önerilir. Bu gereklilik olmayan ürünlerde röntgen çekimi daha serbest yapılabilmektedir. Yazılımdan yazılıma değişebilmekle birlikte ortak özelliklerinden biri ameliyat sonrası sisteme hem deformite parametrelerinin girilmesi hem de kurulan çerçevenin ekstremiteye göre uzaysal konumunun bilgisayar yazılımına tanımlanmasıdır. Bu, ne kadar doğru bir şekilde yapılırsa o kadar az sayıda rezidüel deformite düzeltilmesine gerek kalarak düzeltme tamamlanır. Taylor uzaysal çerçevesinin (Taylor Spatial Frame (Smith\&Nephew, Memphis, TN) yazılımı aşağıda belirtilen bazı parametrelerin de içinde yer alacağı temel özelliklerden oluşmaktadır: Proksimal ve distal halkaların çapı, çubukların tipi ve uzunluğu, "orijin" (origin) ve "karşlık gelen nokta" (corresponding point). [24] CORA (Center of rotation of angulation Deformite merkezi), çoğu zaman orijin olarak seçilmek için uygun bir noktadır (CORAgin). Bir başka ölçüm yöntemi karşılık gelen noktanın orijin olarak seçilmesi$\operatorname{dir}$ (CORAsponding point). Bu sayede translasyon yapılmasına gerek kalmadan düzeltme yapılması mümkün olabilir. Montaj parametrelerinin (Mounting parameters) belirlenmesi gerekir. Uzaysal olarak referans alınan halkanın ortasının orijine olan mesafesinin altı eksen üzerinden tanımlanması gereklidir: anteroposterior, lateral, aksiyel, rotatuvar frame offset. Bu dört montaj parametresine ilave olarak altı deformite parametresi ve üç frame parametresinin de bilgisayara tanımlanması gereklidir. Bu 13 parametrenin ışığında bilgisayar, çubukların gelmesi gereken boyunu hesaplar. Düzeltme hızı ilizarov çerçevesinde olduğu gibi biyolojiye göre belirlenir. TSF yazılımında distraksiyonun 
belirlenmesi gereken risk altındaki yapılar dikkate alınır (Structure at Risk, SAR). TSF'de planlama yapilırken röntgen referans halkasına dik bir biçimde çekilmelidir. Buna yönelik tarif edilmiş çeşitli yöntemler vardır. Ancak en basit olanı referans halkanın kasete iz düşümünün keskin köşeli bir dikdörtgen (kalın düz bir çizgi) şeklinde olacak şekilde ışının ayarlanmasıdır. ${ }^{25-30]}$ Türkiye'de mevcut olan diğer heksapodlar içerisinde Smart Correction'da film çekilirken ışın iki halkanın ortasına denk gelmeli, halkaların kasete olan uzaklığının ve çubukların uzunluğunun da sisteme girilmesi gereklidir. Bu film çekimi sırasında proksimal ve distal halkaların üzerinde röntgen tüpüne en yakın yer alan numara sisteme girilmelidir. Bu doğrultuda sistem bir animasyon oluşturmakta ve bu animasyonun röntgenle birebir örtüşsmesi gereklidir. Eğer bu sağlanabilirse montaj parametresi yazılım tarafından algılanmış olmakta ve başka bir hesaplama yapılmasına gerek kalmaksızın çizelge oluşturulabilmektedir. Spider Frame'de ise röntgen TSF gibi referans halkasına ortogonal olarak çekilmelidir. Parametre girilerek ölçüm yapılabileceği gibi röntgen üzerinden işaretleme yaparak da planlama yapılması mümkündür. Bilgisayar destekli heksapodların ilizarov çerçevesine benzemeyen bir yönü de cihazın çıkarılması aşamasında karşımıza çıkmaktadır. ilizarov çerçevesinde mevcut rodlardan birisinin çıkarılması bir yandan sisteme dinamizasyon sağlayıp öte yandan sistemin sağlamlığını ciddi ölçüde etkilemezken, heksapodlarda çubuklardan birinin bile çıkarılması sistemi tamamen instabil hale getirir. Bu sebeple etkin bir dinamizasyon yapılamaması sistemin en büyük dezavantajlarından birisidir. Bunu aşmak için yeni dizayn edilen ürünlerde buna yönelik geliştirmeler yapılmakla beraber klasik olarak yapılabilecekler tel veya Schanz'ların kademeli olarak çıkarılması veya bilgisayar destekli fiksatör çubuklarının çıkarılıp yerine standart ilizarov rodlarından takılarak klasik dinamizasyon adımlarının takip edilmesidir. Düzeltme sırasında çubukların değiştirilmesi gereken durumlarda iki halkanın arasına aradaki boşluğu destekleyecek bir mekanizma yerleştirilebilir. Ancak başka bir çubuk yerleştirerek değişim yapılacaksa konulacak ekstra çubuğun konulma açısı sebebiyle göreceli olarak instabilite yaratabileceği unutulmamalıdır. ${ }^{[31]}$

\section{BILGISAYAR DESTEKLI FIKSATÖRLER HAKKINDAKI LITERATÜR}

Heksapodların klinik kullanımı hakkında yapılmış yüzlerce çalışma vardır. Pubmed'de "Taylor spatial frame" araması ile yayımlanmış 200'ün üzerinde makaleye ulaşmak mümkündür. ${ }^{[24,32-35]}$ Heksapodların deformite tedavisindeki rolü ve üstünlüğü artık kabul görmüştür. Özellikle kompleks deformitelerin hasta ve cerrah açısından daha az aşamada ve daha kolay bir şekilde düzeltilmesi en büyük avantajıdır. Rotasyonel komponenti olan deformitelerin düzeltilmesinde klasik ilizarov çerçevesine göre kıyas kabul etmez bir üstünlüğü olduğunu söylemek yanlış olmaz. Özellikle deformitenin kompleksitesinin artması ile rezidüel deformitenin arttığı Eren ve ark.'nın ${ }^{[11]}$ çalışmasında gösterilmiştir. Hangi durumlarda klasik ilizarov çerçevesi yerine bilgisayar destekli eksternal fiksatör yapılmasına yönelik bir algoritma geliştiren Cherkashin ve ark. ${ }^{[36]}$, yayımladıkları makalede her ne kadar ayak - ayak bileği cerrahisinde kullanılan farklı çerçeve dizaynları üzerine yoğunlaşmışlarsa da belirttikleri algoritma vücudun diğer kısımlarına da uyarlanabilir. Heksapodların ilizarov sirküler eksternal fiksatöre kıyasla nispeten daha kolay kurulabilir ve kullanılabilir olması yaygınlığının artmasında en büyük faktördür ancak klasik illizarov prensiplerine hakim olmayı ve gereğinde heksapodal fiksatörü klasik ilizarov komponentleri ile kombine etmenin gerekebileceğini unutmamak gerekir. Dolayısıyla bilgisayar destekli heksapodal fiksatörler de klasik ilizarov prensiplerini ve biyolojiyi göz önünde tutarak uygulanmalıdır. Yapılan çalışmalarla heksapodların ilizarov eksternal fiksatörüne göre dayanıklılık açısından geri kalır tarafı olmadığı gösterilmiştir. TSF'nin illizarov çerçevesine göre aksiyel sertliği 1,1 kat, bükülme (bending) sertliği iki kat, torsiyonel sertliği 2,3 kattır. Torsiyonel sertlik açısından TSF ilizarov sistemine göre belirgin olarak daha üstündür. ${ }^{[6,37]}$ TSF'nin özellikle Schanz pinleri (vidaları/çivileri) ile birlikte kullanılması halinde illizarov çerçevesine benzer biyomekanik aksiyel stabilite elde edilebileceği gösterilmiştir. ${ }^{[38,39]}$ Skomoroshko ve ark. yaptıkları çalışmada ilizarov sistemine kıyasla OrthoSUV'nin rijiditesinin daha fazla olduğunu göstermişlerdir. ${ }^{[15]}$ ilave olarak deformiteyi düzeltebilme kesinliği açısından üstünlüğü özellikle rotasyonel komponenti olan kompleks deformitelerde öne çıkmaktadır. Halka-çubuk açısının 30 derecenin altında olmasının stabiliteyi ciddi oranda etkilediği belirtilmiştir. ${ }^{[40]}$

Heksapodların kalıcı tedavi biçimi olarak kullanımlarının yanı sıra biraz pahalı bir yöntem olsa da ameliyatta intraoperatif olarak düzeltmenin akut olarak elde edilmesinde yardımcı bir unsur olarak kullanılması ve kalıcı tedavinin aynı seansta kilitli plak veya intramedüller çivi ile yapılmasına dair bir teknik de tarif edilmiştir [Bilgisayarlı heksapod yardımlı ortopedik cerrahi-Computer hexapod-assisted orthopaedic surgery (chaos)].[41] Kalıcı olarak tedavi amacıyla kullanılacak heksapodlarda bazen intraoperatif olarak manuel bazı düzeltmeler yapılması gerekebilmektedir. Küçük açılanmalar veya translasyonları manuel olarak düzeltmek amacıyla deneme yanılma yoluyla 
çubukları çevirmeye çalışmak çoğu zaman zahmetli olup, bazen ise istenilen sonucun elde edilememesine yol açar. Heidari ve ark. yayımladıkları makale ile, hangi çubukların hangi yönde hareket ettirildiğinde nasıl bir açılanma ya da translasyon yapılabileceğine yönelik pratik bilgiler sağlamaktadırlar. ${ }^{[42]}$

Bilgisayar destekli eksternal fiksatörler gün geçtikçe donanımsal ve yazılımsal olarak gelişmektedirler. Özellikle çocuklarda ve kompleks deformitelerin tedavisinde oynadıkları rolün önemi yadsınamaz. Günümüzde mevcut olan çok çeşitli heksapodal fiksatörler içerisinde kullanılması hedeflenen ürünün özellikleri iyi irdelenmeli ve hem ameliyatın planlanmasında hem de yazılımsal olarak düzeltmenin hesaplanması ve uygulanmasında dikkat edilmesi gereken özelliklere hakim olunmalıdır. Unutulmamalıdır ki başarılı bir sonuç ancak iyi bir deformite analizi yapılarak, distraksiyon osteogenezisinin biyomekanik ve biyolojik prensiplerine sadık kalınarak alınabilir.

\section{KAYNAKLAR}

1. Shtarker H, Volpin G, Stolero J, Kaushansky A, Samchukov M. Correction of combined angular and rotational deformities by the Ilizarov method. Clin Orthop Relat Res 2002;(402):18495. Crossref

2. Dammerer D, Kirschbichler K, Donnan L, Kaufmann G, Krismer M, Biedermann R. Clinical value of the Taylor Spatial Frame: a comparison with the llizarov and Orthofix fixators. J Child Orthop 2011;5(5):343-9. Crossref

3. Manner HM, Huebl M, Radler C, Ganger R, Petje G, Grill F. Accuracy of complex lower-limb deformity correction with external fixation: a comparison of the Taylor Spatial Frame with the Ilizarov ring fixator. J Child Orthop 2007;1(1):55-61. Crossref

4. Calder PR, Faimali M, Goodier WD. The role of external fixation in paediatric limb lengthening and deformity correction. Injury 2019;50 Suppl 1:S18-23. Crossref

5. lobst CA. New Technologies in Pediatric Deformity Correction. Orthop Clin North Am 2019;50(1):77-85. Crossref

6. Paley D. Principles of Deformity Correction, 2nd ed. Berlin, Heidelberg, New York: Springer; 2003.

7. Paley D. History and Science Behind the Six-Axis Correction External Fixation Devices in Orthopaedic Surgery. Oper Tech Orthop 2011;21(2):125-8. Crossref

8. Samchukov M. Personal Communication. 2019.

9. Keshet D, Eidelman M. Clinical utility of the Taylor spatial frame for limb deformities. Orthop Res Rev 2017;9:51-61. Crossref

10. Seide K, Wolter D, Kortmann HR. Fracture reduction and deformity correction with the hexapod Ilizarov fixator. Clin Orthop Relat Res 1999;(363):186-95. Crossref

11. Eren I, Eralp L, Kocaoglu M. Comparative clinical study on deformity correction accuracy of different external fixators. Int Orthop 2013;37(11):2247-52. Crossref

12. Özkul B, Çamurcu Y, Sokucu S, Yavuz U, Akman YE, Demir B. Simultaneous bilateral correction of genu varum with Smart frame. J Orthop Surg (Hong Kong) 2017;25(2):2309499017713915. Crossref
13. Eralp L, Bilen FE, Rozbruch SR, Kocaoglu M, Hammoudi Al. External fixation reconstruction of the residual problems of benign bone tumours. Strategies Trauma Limb Reconstr 2016;11(1):37-49. Crossref

14. Takata M, Vilensky VA, Tsuchiya H, Solomin LN. Foot deformity correction with hexapod external fixator, the Ortho-SUV Frame ${ }^{\mathrm{TM}}$. J Foot Ankle Surg 2013;52(3):324-30. Crossref

15. Skomoroshko PV, Vilensky VA, Hammouda Al, Fletcher MDA, Solomin LN. Mechanical rigidity of the Ortho-SUV frame compared to the llizarov frame in the correction of femoral deformity. Strategies Trauma Limb Reconstr 2015;10(1):511. Crossref

16. Solomin L, Utekhin A, Vilensky V. Deformity Correction and Fracture Treatment by Software-based Ortho-SUV Frame, User Manual. Saint-Petersburg: Vreden Russian Research Institute of Traumatology and Orthopedics "Ortho-SUV» Ltd.; 2013. http://www.ortho-suv.org/razrabotk-eng/orthosuv-manual-engl.pdf

17. Pesenti S, lobst CA, Launay F. Evaluation of the external fixator TrueLok Hexapod System for tibial deformity correction in children. Orthop Traumatol Surg Res 2017;103(5):761-4. Crossref

18. Riganti S, Nasto LA, Mannino S, Marrè Brunenghi G, Boero $\mathrm{S}$. Correction of complex lower limb angular deformities with or without length discrepancy in children using the TL-HEX hexapod system: comparison of clinical and radiographical results. J Pediatr Orthop B 2019;28(3):214-20. Crossref

19. lobst CA. New Trends in Ring Fixators. J Pediatr Orthop 2017;37 Suppl 2:S18-21. Crossref

20. Ferreira N, Birkholtz F. Radiographic analysis of hexapod external fixators: fundamental differences between the Taylor Spatial Frame and TrueLok-Hex. J Med Eng Technol 2015;39(3):173-6. Crossref

21. lobst C, Samchukov M, Cherkashin A. A comparison of deformity correction capabilities in hexapod frame systems. Journal of Limb Lengthening \& Reconstruction JLLR 2016;2(1):29-34. Crossref

22. Alexis F, Herzenberg JE, Nelson SC. Deformity correction in Haiti with the Taylor Spatial Frame. Orthop Clin North Am 2015;46(1):9-19. Crossref

23. Paley D, Herzenberg JE, Tetsworth K, McKie J, Bhave A. Deformity planning for frontal and sagittal plane corrective osteotomies. Orthop Clin North Am 1994;25(3):425-65.

24. Taylor JC. Perioperative planning for two- and three-plane deformities. Foot Ankle Clin 2008;13(1):69-121. Crossref

25. Wright J, Sabah SA, Patel S, Spence G. The silhouette technique: improving post-operative radiographs for planning of correction with a hexapod external fixator. Strategies Trauma Limb Reconstr 2017;12(2):127-31. Crossref

26. Gantsoudes GD, Fragomen AT, Rozbruch SR. Intraoperative measurement of mounting parameters for the Taylor Spatial Frame. J Orthop Trauma 2010;24(4):258-62. Crossref

27. Deakin DE, Rolands T, Taylor A. A frame-mounted X-ray guide for the Taylor Spatial Frame. Ann R Coll Surg Engl 2007;89(7):729. Crossref

28. Kanellopoulos AD, Mavrogenis AF, Kanellopoulos ND, Magnissalis EA, Papagelopoulos PJ. A guide frame for the Taylor Spatial Frame. J Orthop Trauma 2009;23(7):537-40. Crossref

29. Kucukkaya M, Karakoyun O, Armagan R, Kuzgun U. Calculating the mounting parameters for Taylor Spatial Frame correction using computed tomography. J Orthop Trauma 2011;25(7):449-52. Crossref 
30. Park DH, Bradish CF. An intraoperative method of calculating the mounting parameters for the Taylor Spatial Frame using the image intensifier. Ann R Coll Surg Engl 2011;93(3):2601. Crossref

31. Jenkins PJ, Bulkeley MG, Mackenzie SP, Simpson HR. Preventing instability of the Taylor Spatial Frame (TSF) during a strut change. J Orthop Trauma 2012;26(4):258-60. Crossref

32. Eidelman M, Bialik V, Katzman A. The use of the Taylor spatial frame in adolescent Blount's disease: is fibular osteotomy necessary? J Child Orthop 2008;2(3):199-204. Crossref

33. Marangoz S, Feldman DS, Sala DA, Hyman JE, Vitale MG. Femoral deformity correction in children and young adults using Taylor Spatial Frame. Clin Orthop Relat Res 2008;466(12):3018-24. Crossref

34. Küçükkaya $M$, Karakoyun $\mathrm{O}$, Armağan $\mathrm{R}$, Kuzgun $U$. Correction of complex lower extremity deformities with the use of the Ilizarov-Taylor spatial frame. Acta Orthop Traumatol Turc 2009;43(1):1-6. http://www.aott.org.tr/en/ correction-of-complex-lower-extremity-deformities-with-theuse-of-the-ilizarovtaylor-spatial-frame-164503

35. Belthur MV, lobst CA, Bor N, Segev E, Eidelman M, Standard SC, Herzenberg JE. Correction of Cubitus Varus After Pediatric Supracondylar Elbow Fracture: Alternative Method Using the Taylor Spatial Frame. J Pediatr Orthop 2016;36(6):608-17. Crossref
36. Cherkashin AM, Samchukov ML, Birkholts F. Treatment Strategies and Frame Configurations in the Management of Foot and Ankle Deformities. Clin Podiatr Med Surg 2018;35(4):423-42. Crossref

37. Tan B, Shanmugam R, Gunalan R, Chua Y, Hossain G, Saw A. A Biomechanical Comparison between Taylor's Spatial Frame and Ilizarov External Fixator. Malays Orthop J 2014;8(2):359. Crossref

38. Henderson DJ, Rushbrook JL, Harwood PJ, Stewart TD. What Are the Biomechanical Properties of the Taylor Spatial Frame ${ }^{\mathrm{TM}}$ ? Clin Orthop Relat Res 2017;475(5):1472-82. Crossref

39. Kold S. CORR Insights: What Are the Biomechanical Properties of the Taylor Spatial Frame ${ }^{\mathrm{TM}}$ ? Clin Orthop Relat Res 2017;475(5):1483-5. Crossref

40. Henderson ER, Feldman DS, Lusk C, van Bosse HJ, Sala D, Kummer FJ. Conformational instability of the Taylor spatial frame: a case report and biomechanical study. J Pediatr Orthop 2008;28(4):471-7. Crossref

41. Hughes A, Heidari N, Mitchell S, Livingstone J, Jackson M, Atkins R, Monsell F. Computer hexapod-assisted orthopaedic surgery provides a predictable and safe method of femoral deformity correction. Bone Joint J 2017;99-B(2):283-8. Crossref

42. Heidari N, Hughes A, Atkins RM. Intra-operative correction of Taylor Spatial Frame without a computer. J Orthop Trauma 2013;27(2):e42-4. Crossref 